Article

\title{
An Optimization Model Fitting the Neighborhood Sustainability Assessment Tools
}

\author{
Carmela Gargiulo ${ }^{1, *}$, Antonio Sforza ${ }^{2}$, Claudio Sterle ${ }^{2,3}$ and Floriana Zucaro ${ }^{1}$ \\ 1 Department of Civil, Architectural and Environmental Engineering, University of Naples Federico II 1, \\ 80125 Naples, Italy; floriana.zucaro@unina.it \\ 2 Department of Electrical Engineering and Information Technology, University of Naples Federico II 2, \\ 80125 Naples, Italy; sforza@unina.it (A.S.); claudio.sterle@unina.it (C.S.) \\ 3 IASI-(Institute for Systems Analysis and Computer Science) of the Italian National Research Council, \\ 00185 Rome, Italy \\ * Correspondence: gargiulo@unina.it; Tel.: +39-081-768-2308
}

Received: 31 July 2018; Accepted: 16 September 2018; Published: 20 September 2018

check for updates

\begin{abstract}
The phenomenon of rapid and unplanned urban growth, driven by the migration from rural to urban areas, has hindered healthy urbanization and undermined sustainable development. Sustainability assessment has become one of the popular terms in different fields, especially in architecture and urban planning, and world leading urban sustainability assessment tools have been proposed. Each tool is based on a set of weighted evaluation parameters, related to some main sustainability dimension (environment, economy, society ... ), and requires to reach a sustainability threshold. In this paper, after a brief review of the state of the art, a linear optimization model is presented, which aimed to find the minimum set of parameters needed to guarantee the sustainability threshold for each tool, taking into account all the sustainability dimensions. The model has been positively experienced with 144 input parameters belonging to five assessment tools. The tests prove that this procedure is able to summarize and overcome the choices made by the certifying bodies. Indeed the proposed optimization model selected 26 parameters of the five tools. The majority of the selected parameters are related to the environmental emergency that in recent decades has characterized—and still affects—urban systems.
\end{abstract}

Keywords: urban sustainability; neighborhood sustainability assessment; optimization model

\section{Introduction}

The ecological dimension of the concept of sustainability [1] quickly encompassed the economic and social ones, according to the fact that "our struggle for sustainability will be won or lost in cities" [2] (p. 3). To guarantee that urban sustainability results in the simultaneous achievement of these three aspects, local administrators have begun to assess and certify the sustainability of the different proposals of urban transformation (plans and/or projects).

In recent years, consulting companies and non-governmental bodies (at times universities) have developed techniques and procedures for assessing the sustainability of urban transformation plans and projects. If an ex-ante evaluation by local administrations is now an instance of good practice widespread at the international level, to obtain a form of certification attesting the sustainability of the proposed transformation choices, the attention given by the scientific community to many of the techniques and tools seems to be lacking and certainly not exhaustive. Few studies have tried to investigate and compare these techniques with an analytical approach, and they failed to secure the expected results due to the lack of information about: (i) Criteria and selection procedures of parameters; (ii) the measurement and setting of weights and scores to parameters; (iii) the shared definition of sustainability certification thresholds. 
In this context, on the one hand, it is necessary to deepen the scientific debate on these techniques; on the other hand, it is also necessary to provide technicians, professionals and local administrators with reliable methods for ex-ante evaluation of the transformation choices without resorting to onerous and in many ways still "obscure" certification procedures. The objective of the present work is to select a set of parameters which may give a significant measure of the urban sustainability of the proposals (plans and/or urban projects at the neighborhood scale), taking into account the parameters used by five international protocols, generally adopted by users of such practice tools. To this aim a linear optimization model has been formulated to identify a reduced set of parameters, which is able to achieve the minimum sustainability threshold for each of the considered tool. At the same time, the output of the model helps to measure (a) their significance with respect to the initial set of parameters, and (b) to interpret the relationships between them.

The paper is structured as follows: Section 2 offers a review of the main certification procedures for sustainable assessment; Section 3 describes the methodology used in this study and the proposed optimization model; Section 4 discusses the main findings and, finally, the conclusions of the study are presented.

\section{State of Art}

The second half of the 20th century and the beginning of the 21st are advocated as the "urban" centuries, according to the rapid and continuous rate of urbanization characterizing more than half the world cities [3]. This definition emphasizes the need and the urgency of dealing with the numerous threats to sustainability. Issues such as climate change, energy saving and energy supplies, water and air pollution are some of the main challenges that local decision-makers have to contribute to resolve, as urban areas are considered as driving forces for a more sustainable development [4].

The aim of avoiding the whole depletion of natural resources has promoted the proposal of different models of urban development, such as eco-cities, low-carbon cities, green-energy cities, and smart cities. Their main starting point is that social, economic and ecological development "can go hand in hand, although it is not safe to assume that a win-win-win is always the logical outcome of modern urban transformation" [5,6].

The application of these sustainability approaches to the planning process has stimulated the development of certification procedures and tools based on criteria, parameters and indicators at different levels, from single building to neighborhood and to the whole city. All these techniques have become widespread since the beginning of the 21st century in the wake of Agenda 21. Local decision makers have begun to assess and benchmark their city performance first, and then urban transformation projects, for territorial marketing reasons mainly, so as to promote their good practices and their success in reaching sustainability goals [7,8]. In fact, benchmarks, metrics and ratings seek to communicate the outcomes of urban policies in an easy way, by summarizing and simplifying the complex and broad volume of data acquired by a likewise wide range of sources [9-11].

Most sustainability assessment procedures were initially developed for the building level, in order to evaluate the energy performance of each single built element of an urban area. BREEAM and LEED were, respectively, the first European and American building sustainability assessment methods developed in the 1990s. Then, they and the other assessment methods developed since the past century were soon extended to both the spatial scale and the whole building lifecycle, by taking into consideration economic, environmental and ecological aspects. The double shift from the building to a broader level and from the energy concern to the whole sustainability issue was linked to different reasons: (i) The need for reducing energy consumption is just one of the environmental matters that affect urban areas and local administrators have to deal with; (ii) buildings, as part of a city, can result in a limiting scale of analysis if compared to the complex relations between them and all the urban settlement, according to the fact that "it is the cities/neighborhoods as a whole that have a more or less sustainable behavior" [12] (p. 12). 
Among the possible analysis levels of urban sustainability assessment (building, neighborhood, city), the neighborhood level is the most burgeoning, as it can represent the most appropriate scale that can consider all three sustainability dimensions together with the complex building-urban and city interactions that leads to results that are still too complex to evaluate [13-16]. It can be stated that the neighborhood level provides a twofold effect: (i) It allows researchers to overcome possible barriers related to the difficulty of taking into account context-specific problems that the broader spatial level of the whole city can implicate; (ii) it considers social and community aspects as is likely to be the minimum level where the economies of scale and issues such as employment and job-housing proximity can be better exploited $[14,17,18]$.

Focusing the attention on the neighborhood level, the first sustainability assessment procedure HQE2R was developed in Europe during the early 2000s. More recently, other certification techniques were elaborated in Japan and USA (e.g., CASBEE, BREEAM, DGNB, LEED), up to 2012 when the pilot version of Green Star Communities was launched in Australia. To date, numerous certification for evaluating urban sustainability are currently available and actively in use worldwide and mostly they are "the expansion and adaptation of already established building sustainability assessment and certification systems to accommodate the complexities of the urban scale" [19] (p. 548).

The increasing popularity of urban neighborhood sustainability assessment practices (or Neighborhood Sustainability Assessment Tools-NSA-according to literature, where neighborhood refers to a portion of an urban settlement identified both by administrative boundaries, e.g., district, and physical and functional characteristics that allow to identity a specific area) has been attracting the attention of the scientific community and, as a result, a plethora of research has been developed. The main research branches in this field can be synthesized as follows:

1. Numerous studies investigating their theoretical aspects, by mainly comparing differences and similarities in terms of dimensions of sustainability considered, parameters used and weights assigned [7,20-24]. This kind of study chiefly allowed for the identification of the bias and weakness of criteria and parameters, prevalence of one sustainability dimension (generally environmental $[20,25,26])$, and the lack of transparency of the assessment methodology $[7,27]$.

2. A young but growing body of research is related to the ease and flexibility of use of these procedures in different contesxs, by emphasizing the need of mutual links and public participation [28-31] and the fact that some criteria were used more frequently than others. This variation in what is prioritized and what is not underlines that a broad set of parameters does not guarantee the sustainability goal of a project [32,33].

3. Studies recommending a system of parameters and/or indicators to assess urban sustainability at the neighborhood scale, by collecting them from several sources [34-37], setting out a reliable selection methodology [12,38,39]. Actually, this last field of research is quite new at the neighborhood scale, while it is discussed in more detail in the scientific literature related to urban sustainability as a whole [40-42].

This work does not concern the first two lines of research since the first one's results are already consolidated and the second one is well covered by the already available tools and by the related review. The work can be referred to as in the third line of research, even though with a more applicative and experimental perspective. In fact, it refers to the development of a methodology aimed at selecting the most suitable set of parameters from the dataset of urban neighborhood sustainability assessment procedures and providing information from the original dataset.

It is worth noting that the authors are not willing to develop a new sustainability assessment procedure, but their aim is to propose to local administrators an alternative to the usage of expensive tools, by an analytical procedure which is able to summarize and overcome the "opaque" choices made by the certifying bodies. 


\section{Methodology}

In order to identify (by methods of scientific reliability) a reduced set of parameters that are able to assess the sustainability of the hypotheses of transformation contained in an urban project, this work proposes a linear optimization model. Staring from a set of eligible solutions (the initial set of parameters), this model is able to find the final set of parameters which satisfies a series of conditions, minimizing the objective function related to the parameters of some certification sustainability assessment procedures. All the relations (constraints) between the quantities involved (parameters) are linear, including the value of the objective function. Moreover, the model parameters are not bound to assume discrete sets of values (for example only integer values); that is, they can assume real values. The application of linear optimization techniques to decisions related to the governance of urban and territorial transformations has proved to be extremely valuable: It opens up the possibility of choosing coherently with certain (often limited) preferences, information and resources, available to public decision makers. The theoretical foundation of this type of analysis and models is based on the assumption that every choice made by any subject implies (or is determined by) the utility gained from pursuing that choice (expressed as an aggregate value), and that when coming to a final decision, the decision maker tends to maximize it (utility theory, [43]).

The model is therefore in line with the objectives of this research work, which is to guarantee the reliability of the assessment of sustainability of an urban transformation project at the neighborhood scale, minimizing the information necessary to make a reliable judgment (effectively selecting the parameters to be considered).

Figure 1 resumes the procedure framework and the main four steps of the methodology used: Selecting the certification sustainability assessment procedures, classifying sustainability dimensions and parameters, defining the optimization model and obtaining the findings.

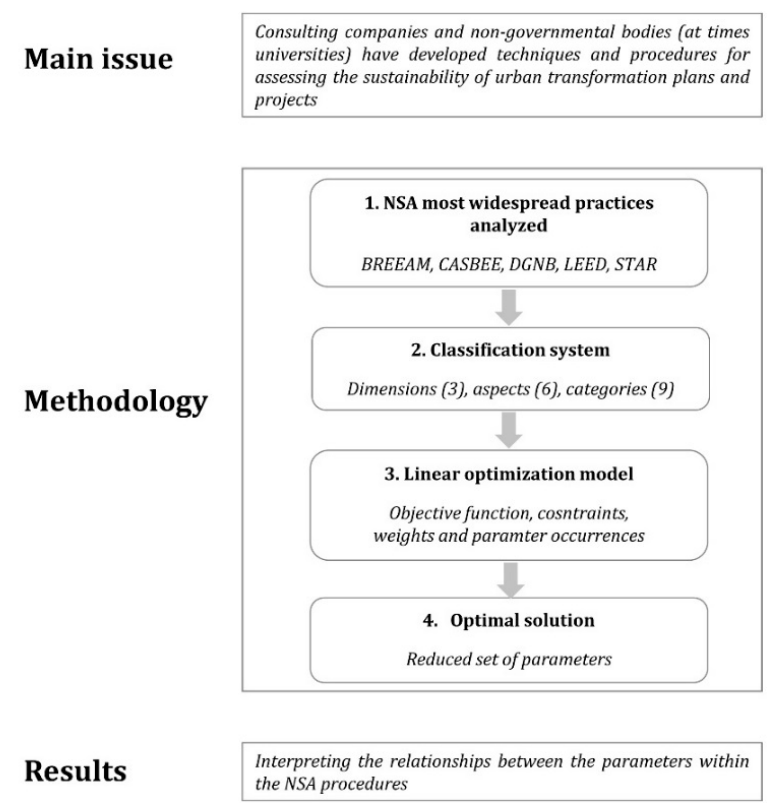

Figure 1. Procedure framework.

\subsection{Most Widespread NSA Procedures Analysed}

This study has chosen five international procedures/tools, according to a previous study on the issue [44]: BREEAM community, CASBEE urban development, DGNB for urban development, LEED and STAR community. The selected assessment protocols are among the most widespread both for their use by local administrators and for academic research (e.g., [25,31,45]). Table 1 collects the main features of the urban sustainability assessment tool, including: Last version, number of items, verification fee, assessment time and period of validity of certification. 
Table 1. Summary of the sustainability assessment tool characteristics.

\begin{tabular}{|c|c|c|c|c|c|c|c|c|c|c|}
\hline \multirow[b]{2}{*}{ Sustainability Assessment Tool } & \multicolumn{2}{|c|}{ First Version Year } & \multicolumn{2}{|c|}{ Last Version Year } & \multirow[b]{2}{*}{ Developers } & \multirow[b]{2}{*}{$\mathbf{N}^{\circ}$ Items } & \multirow[b]{2}{*}{$\mathbf{N}^{\circ}$ Parameters } & \multirow[b]{2}{*}{ Certification Rating } & \multirow[b]{2}{*}{ Verification Fee } & \multirow{2}{*}{$\begin{array}{l}\text { Period Validity } \\
\text { of Certification }\end{array}$} \\
\hline & $\begin{array}{c}\text { Building } \\
\text { Scale }\end{array}$ & $\begin{array}{l}\text { Neighborhood } \\
\text { Scale }\end{array}$ & $\begin{array}{c}\text { Building } \\
\text { Scale }\end{array}$ & $\begin{array}{l}\text { Neighborhood } \\
\text { Scale }\end{array}$ & & & & & & \\
\hline $\begin{array}{c}\text { BREEAM-Building Research } \\
\text { Establishment Environmental } \\
\text { Assessment Method }\end{array}$ & 1990 & 2008 & 2018 & 2012 & BRE Global Ltd. & 5 & 40 & $\begin{array}{c}5 \\
\text { pass } \\
\text { good } \\
\text { very good } \\
\text { excellent } \\
\text { outstanding } \\
\end{array}$ & $\sim € 750$ (minimum) & Until 5 years \\
\hline $\begin{array}{c}\text { CASBEE (urban } \\
\text { development)-Comprehensive } \\
\text { Assessment System for Building } \\
\text { Environmental Efficiency }\end{array}$ & 2002 & 2006 & 2014 & 2014 & $\begin{array}{l}\text { JSBC (Japan Sustainable } \\
\text { Building Consortium), Institute } \\
\text { for Building Environment and } \\
\text { Energy Conservation (IBEC) }\end{array}$ & 3 & 30 & $\begin{array}{c}4 \\
\text { B- fairly poor } \\
\text { B+ good } \\
\text { A very good } \\
\text { S excellent } \\
\end{array}$ & $\sim € 5400-14,300$ & 3 years \\
\hline $\begin{array}{l}\text { DGNB_-Deutsche Gesellschaft für } \\
\text { achhaltiges Bauen }\end{array}$ & 2008 & 2008 & 2018 & 2012 & $\begin{array}{c}\text { German Sustainable Building } \\
\text { Council }\end{array}$ & 5 & 36 & $\begin{array}{c}3 \\
\text { bronze } \\
\text { silver } \\
\text { gold }\end{array}$ & $\begin{array}{c}\sim € 4200 \\
\text { (minimum) }\end{array}$ & $\sim 3$ years \\
\hline $\begin{array}{l}\text { LEED (ND)-Leadership in Energy } \\
\text { and Environmental Design }\end{array}$ & 1998 & 2007 & 2018 & 2016 & $\begin{array}{l}\text { United States Green Building } \\
\text { Council }\end{array}$ & 5 & 56 & $\begin{array}{c} \\
\text { certified } \\
\text { silver } \\
\text { gold } \\
\text { platinum } \\
\end{array}$ & $\begin{array}{c}\sim € 25,000 \\
\text { (minimum) }\end{array}$ & 5 years \\
\hline $\begin{array}{l}\text { STAR (community rating } \\
\text { system)-Sustainability Tool for } \\
\text { Assessing and Rating communities }\end{array}$ & - & - & 2012 & 2015 & $\begin{array}{l}\text { Star Communities nonprofit } \\
\text { organization }\end{array}$ & 7 & 48 & $\begin{array}{l}3 \\
\text { Certified 3-STAR } \\
\text { Certified 4-STAR } \\
\text { Certified 5-STAR }\end{array}$ & $\sim € 2550$ & 3 years \\
\hline
\end{tabular}


Although a comparison of the five sustainability assessment procedures studied is not the aim of this work, it may be interesting to briefly discuss some aspects related to the selection of their criteria and sustainability parameters with related weights. This further information is aimed at underlying the weaknesses of the NSA procedures identified in Section 1 and moreover how these gaps can be partially overcome by the linear optimization model proposed below.

Generally, the parameters are defined by surveying different stakeholders whose evaluations can presumably depend on their own interests. As a result, this approach can be characterized by a lack of objectivity and bias, at the expense of the most vulnerable parties or aspects [22,27,46].

Apart from CASBEE, which uses a more complex scoring system for its three items, the other NSA procedures determine the final score for the sustainability certification rating by calculating the arithmetic mean of the total scores of their themes (obtained by multiplying the weights by the number of credits available for that specific theme).

As some studies showed [7,16,31], this "vague" kind of weighting and rating can allow researchers to obtain the first level of certification by only satisfying the criteria (and related parameters) with the highest weights.

\subsection{Classification System}

Although all procedures are designed to assess urban sustainability, this objective is pursued in different ways. All the themes ("broad topics of concern to sustainability" [8] (p. 77)), criteria ("the touchstones by which a sustainability indicator is evaluated" [16] (p. 34)), and parameters ("variables that provide specific measurements" [8] (p. 77)) examined refer to different forms of categorization.

After having identified the procedures under study, the successive step of the methodology was focused on the definition of a parameters classification system common to all five procedures analyzed. This classification system consists of three different groups: Dimensions, aspects and categories (Figure 2). The "dimensions" represent the three pillars of sustainability: Environment, society and economy; the "aspects" refer to the main components in which each dimension can be articulated; the "categories" express "urban resources" and "built environment" aspects, both of key concern for this work.

Based on these three classification groups, each parameter has been assigned to only one category or aspect depending on which part of sustainability it can measure. The reclassification was carried out by making a comparison and a necessary evaluation of the description of each parameter within each procedure to ensure that a parameter fits the most significantly relevant aspect or category.

Considering the set constituted by the parameters contained in the guidelines and in the manuals of the assessment procedures under study, it appears to be wider than the set of inputs of the optimization model (217 against 144), as there are parameters that measure the same aspect or category though they are under different names. For this reason, the 217 parameters classified have been re-examined and, where necessary, renamed with a nomenclature common to all procedures, in order not to exclude or repeatedly count one of them, thus achieving the set of 144 input parameters constituting the input of the optimization model.

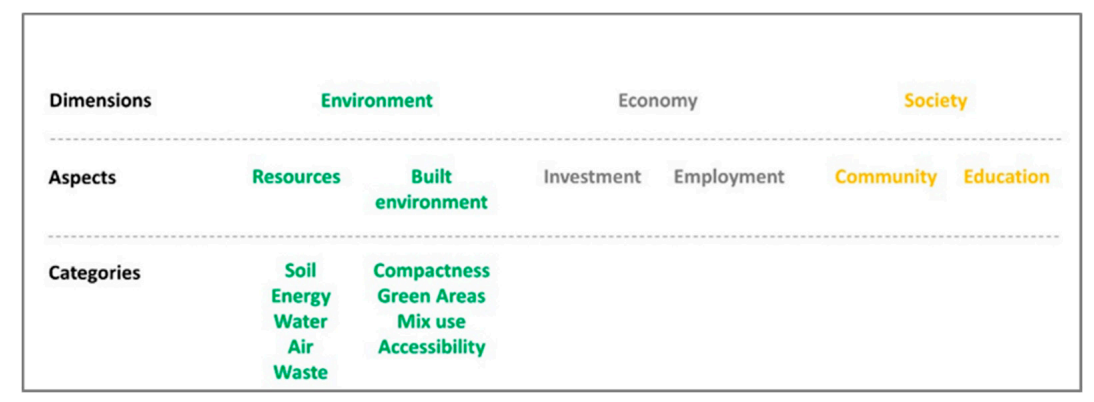

Figure 2. Classification system. 
This can be better explained through some examples. The parameter biodiversity (soil "category") occurs in all the five procedures that refer to it to increase in scale of existing habitats (BREEAM), maintain the urban ecosystem habitat, (STAR and DGNB), conserve pre-existing on-site habitat for a variety of life forms (LEED and CASBEE). At the same time, the parameter inclusive design (compactness "category") is common to BREEAM, DGNB and LEED that refer to it to encourage the construction of a built environment that optimizes accessibility (LEED) and ensures inclusion and access in the design of the external and internal environment (BREEAM and DGNB).

\subsection{Linear Optimization Model}

Upon completion of the parameter classification, the linear optimization model has been developed by formulating the objective function to be optimized, the input parameters and the constraints to be respected.

The linear optimization model used has been conformed with reference to an objective minimization function, in line with the objective of identifying the minimum number of parameters that must constitute the output set. Furthermore, the formulation of the objective function and constraints have been made according the different sets, parameters and variables which the model refers to and are listed below:

Sets

- $I$ is the set of the procedures $1, \ldots, 5$

- $J$ is the set of the procedure parameters

- $K$ is the set of the sustainability dimensions $1, \ldots, 3$

- $J_{i} \subset J$ is the set of the parameters of the procedure $j$ belonging to $J$

- $J_{k} \subset J$ is the set of the parameters of the dimension $k$ of the procedure $j$ belonging to $J$

Parameters and variables

- $a_{i j} \forall I \in I$ and $\forall j \in J$

- $w_{j} \forall j \in J$

- $x_{j}=\{1,144\} \forall j \in J$

- $k_{i}$ is the bound certification value $\forall i \in I$

- $l_{k}=\{19,2,5\} \forall k \in K$

Model

$$
\operatorname{Minz}=\sum_{j \in J} x_{j} \quad \forall j \in J
$$

subject to

$$
\begin{array}{cl}
\sum_{j \in J} a_{i j} x_{j} \geq k_{i} & \forall i \in I, \\
\sum_{j \in j_{k}} x_{j} \geq l_{k} \quad \forall k \in K, \quad \forall j \in J
\end{array}
$$

The objective function (1) expresses the minimization of the number of parameters that must constitute the output set of the optimization model. The parameters $x_{j}$ are 144 . They correspond to all those used by the five procedures under study.

Constraints (2) and (3) denote, generically, the constraints that the model must respect in the search for the optimal solution. In this case, the coefficients $a_{i j}$ are the weights that each of the five evaluation procedures associate with each parameter $x_{j}$, while the coefficients $w_{j}$ are the sum of the occurrences of each parameter in the five procedures. These occurrence values are not present in the model, but they are used in the definition of coefficients $a_{i j}$. Indeed, the weights assigned by each procedure $\left(a_{i j}\right)$ allow for taking into account the importance given by each protocol to each parameter, 
as well as their occurrences, which provide information on their representativeness, since the higher $w_{j}$ is, the more significant that parameter is for one or more procedures.

For the assignment of parameters to a single aspect or category, the identification of the weight attributed by each procedure to each of its parameters was made referring to the manuals available online, or in case the required information was not available, the system coordinator was contacted.

The Constraint (2), one for each procedure, are lower limit constraints that require the achievement of the minimum score necessary to obtain the corresponding certification of sustainability. Each procedure, in fact, defines its own certification rating benchmark system, divided into several levels (Table 1) in order to "enable a client or other stakeholder to compare an individual developments performance with other rated developments" [47] (p. 26). The presence of this constraint ensures that the set of parameters identified by the optimization model is such that it meets the minimum sustainability threshold of each of five procedures.

The Constraints (3) identify, for each of the three dimensions of sustainability, a minimum number of parameters equal to at least the minimum number of parameters in each dimension $\left(l_{k}\right)$ for all five procedures (Table 2). This ensures that the optimal solution consists of parameters that cover all three dimensions of sustainability.

Figure 3 shows the input matrix $(5 \times 144)$ of the optimization model, consisting of the parameters on the columns according to the related aspects and categories, the procedures on the lines and their weights (and frequency) at the intersections.

Table 2. Number of parameters for each sustainability dimension and for each procedure.

\begin{tabular}{ccccc}
\hline & Environment & Economy & Society & Tot. \\
\hline BREEAM & 25 & $\mathbf{2}$ & 14 & 41 \\
\hline CASBEE & 29 & 4 & 14 & 47 \\
\hline DGNB & $\mathbf{1 9}$ & 3 & 10 & 32 \\
\hline LEED & 36 & 3 & $\mathbf{5}$ & 44 \\
\hline STAR & 20 & 6 & 27 & 53 \\
\hline \multirow{2}{*}{ Tot. } & 129 & 18 & 70 & 217 \\
& 83 & 17 & 44 & 144
\end{tabular}

The bold numbers are those used for Constraints (3). The italic numbers refer to the total number of parameters for the three sustainability dimensions according to the proposed classification system.

\subsection{Solution of the Linear Optimization Model}

The linear optimization model was implemented using Xpress-IVE and solved using Xpress-MP 8.4 ILP solver with default setting. The experimentation has been performed on an Intel(R) Core(TM) i7-8700k, $3.70 \mathrm{GHz}, 16.00 \mathrm{~GB}$ of RAM. The above described problem has been solved with negligible computation time and the obtained results are detailed and discussed in next section. 


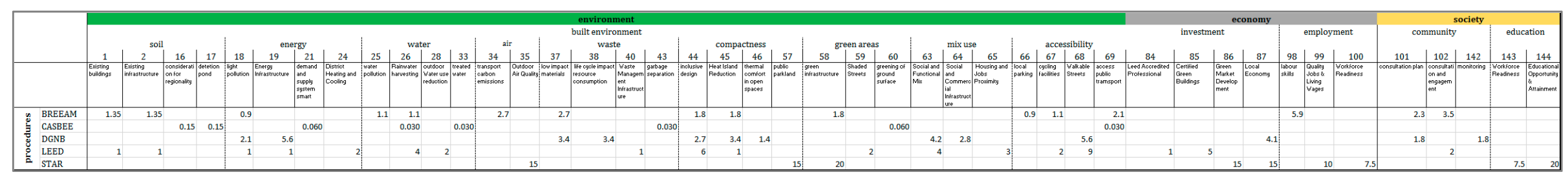

Figure 3. Example of weight matrix of the linear optimization model. 


\section{Results}

Figure 4 shows the parameter set output. The linear model selected 26 parameters that cover all categories, except for the air category. Starting from the reading of the output parameters related to the first "resource", these evaluate the soil from both the eco-systemic and anthropic point of view. Parameters 4, 5 and 13, in fact, refer to soil as a natural resource that should be preserved (13) when making urban transformation choices, so as to ensure its ecological functions, such as biodiversity conservation (5), adjustment and maintenance of the quality of water and nutrients (4). Parameters 2, 3 and 6 refer to soil as a "physical substratum of human activities" [48] (p. 44). The reuse of infrastructure (e.g., rail transport system, water purification channels), as well as the location of new activities in areas where the soil has already been sealed or otherwise transformed (3), and the regeneration of dismissed industrial areas (6) are parameters that help direct an urban transformation hypothesis towards a more sustainable and more efficient use of the soil resource. In particular, parameters 2 and 3 ensure that the distribution of networks (2) and activities (3) within a portion of the municipal territory and, indirectly, of physical and functional accessibility of the area subject to evaluation are taken into account.

The categories of energy, water and waste are valued above all in terms of the efficiency of both use (22, 29 and 39) and distribution (19), in such a way as to contribute to the reduction of the ecological footprint of urban systems $[49,50]$. The categories of energy and water are also assessed with regard to pollution (light pollution and groundwater contamination), in order to safeguard human health and to contribute to improving urban environmental quality.

Moving from natural resources to the physical characteristics prevailing in an urban area, the parameters of the compactness category evaluate the organization and use of existing spaces and existing and/or planned buildings (44, 49 and 52). These three parameters, in fact, describe the design and the urban structure that should be geared to optimize uses (52), accessibility (44) and to improve the livability (9) of the area being transformed.

The aspects that contribute to making a more livable urban system also include the ecological and environmental infrastructural endowments, assessed here through the single parameter (58) related to the presence of green areas. This parameter refers to the greenery not just as equipment, but as a network system able to bring benefits of microclimatic regulation and environmental comfort, taking into account the "new" role that scholars and institutions attribute to the greenery to face the challenges of resilience and adaptation to climate changes [51-53].

The parameters that evaluate the last category of environment assess the accessibility with respect to the quality of the interaction between the activities located on the territory and the pedestrian movement opportunities (68) or through the public rail transport system. In practice, accessibility appears to be evaluated considering the pedestrian usability of the built space rather than the efficiency of the transport system, in order to draw attention to the relationships between the built environment and the domains of well-being [54,55].

As regards to the economic dimension, the two output parameters assess the presence of local productive activities in order to enhance existing local resources and make the community benefit from the relative economic returns (87). Furthermore, economic development on a local scale must be based on environmentally friendly production "capable of ensuring the reparability, longevity and recyclability of products right from the start of the supply chain, as well as ensuring energy efficiency", in alignment with the most recent European guidelines (e.g., COMMUNICATION (2011) 571 and COMMUNICATION (2015) 614/2).

The last aspect of the society dimension is evaluated through five parameters aimed at ensuring an inclusive, fair and resilient urban transformation. The parameters 102 and 119, in fact, are related to the participation and involvement of the local population in the decision and action phases (namely, choice and implementation of urban transformation interventions), especially regarding the design, location and functional organization of public spaces (119) in order to make communities harmonious, healthy and socially inclusive. To foster a socially inclusive and equal community, parameter 102 assesses 
the presence of affordable housing provisions for all residents. Finally, communities should increase their resilience (115) and ecological value (118) and so these two parameters assess the presence of services, facilities and regulations aimed at better preparing for climate change adaptation and reducing environmental threats.

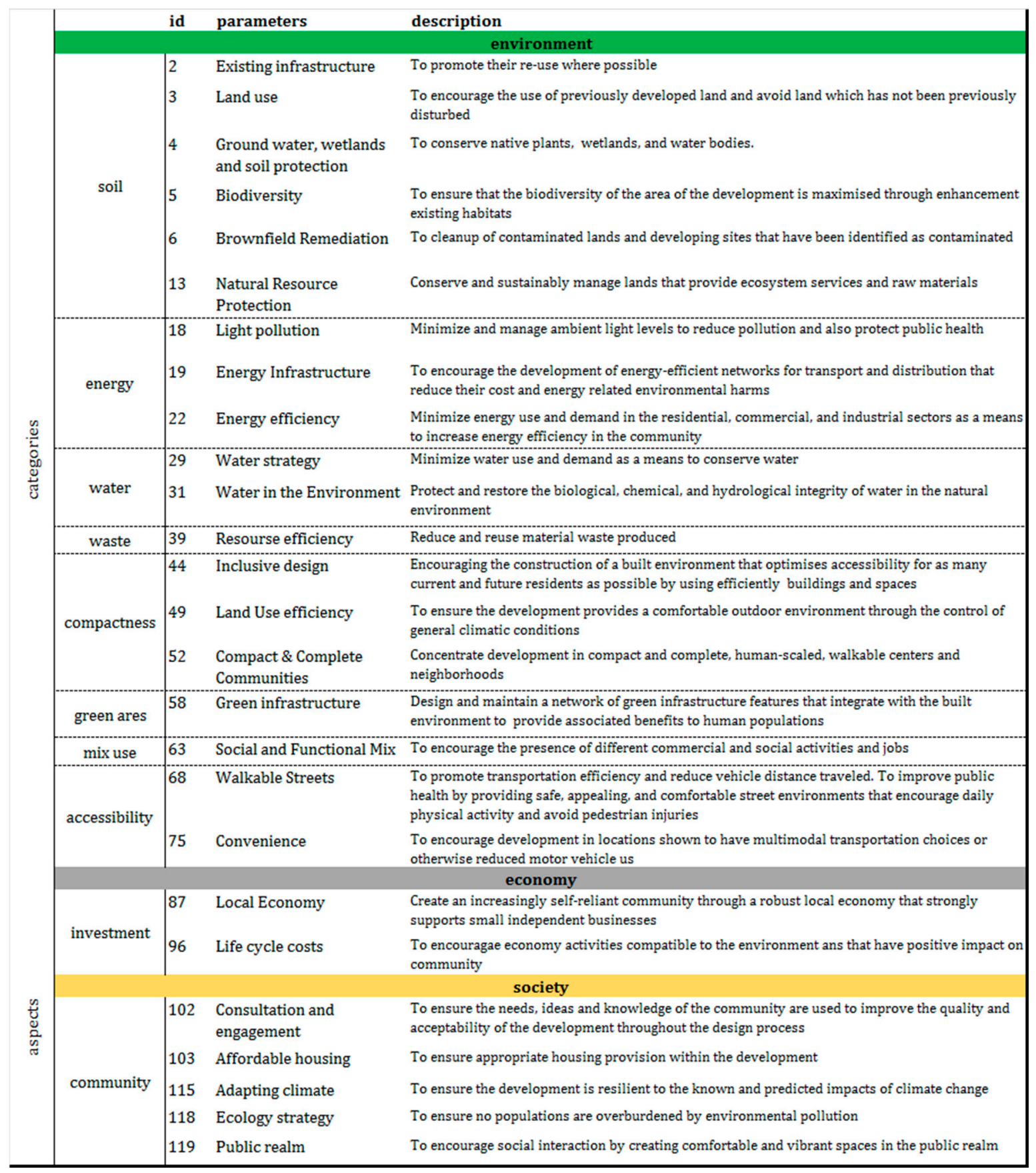

Figure 4. Parameter set output.

\section{Discussion and Conclusions}

Since the 1987 first definition of sustainable development, approaches, paradigms, parameters, indicators and models have been developing in order to boost the implementation of urban sustainability. After almost 25 years of debate, academics, practitioners and international organizations 
are still investigating what the sustainability assessment procedures should be able to measure and to what extent $[46,56,57]$.

The use of these widespread forms of certification produces considerable advantages in terms of publicity and marketing for developers and local decision makers and this should create some concerns $[16,58]$. In this respect the authors agree with Boyle and Elgert $[10,46]$, who claim that the objective of declaring sustainability to be a hypothesis of urban transformation in such a way as to meet the favor of the stakeholders and the local community—thus facilitating its realization-entails the risk of making sustainability become just a brand to be shared or a "label" to grab, underestimating the multiple and essential efficiency, saving, greening and conservation requirements that this concept implies $[59,60]$.

Furthermore, the authors of this work are well aware that the development of a technique for assessing urban sustainability cannot be influenced by the culture, needs and aspirations of the territorial context of reference. They are also certainly aware that the methodological soundness, the transparency and reliability of the information used are fundamental prerequisites to ensure that the transformation choices of an urban area will be sustainable. In order to contribute to broadening the scientific debate on these techniques on the one hand, and to provide useful elements for the improvement or development of future protocols on the other, this research work was aimed at identifying a reduced set of parameters that are able to evaluate the urban sustainability of the proposals (plans and/or urban projects at the neighborhood scale), with reference to the variables used by five international protocols.

The environmental emergency that in recent decades has characterized—and still affects—urban systems (albeit in relation to different problems) connects the majority of the output parameters of the proposed linear optimization model, belonging to different categories. Biodiversity growth, efficient use of resources, adaptation to climate change, improvement of the urban microclimate are among the key recurring issues assessed by the set of parameters (Figure 4) and therefore an urban transformation project cannot but help to solve them. In particular, in regards to the soil resource, it can be stated that the protection of its biodiversity, as well as the resource itself, are objectives to be pursued with a higher priority than others such as its regeneration and the reduction of its (often) indiscriminate consumption (see Figure 4, soil category). However, turning attention to the other categories of the environment dimension, the anthropic value of the soil resource (which refers to the built environment already mentioned above) is assessed indirectly through parameters related to the space-functional system of the city that take account of the organization of the adapted spaces, the distribution of the activities and their accessibility: In sum, of the overall structure of the urban system. The set of networks and built spaces is also assessed in relation to the quality of individual and collective life in order to enhance the sense of community and encourage social interaction.

The scientific rigor and reliability underlying this work reveal its main strengths:

- the proposed parameter set is the output of an analytical procedure that shows more elements of rigor and reliability than the "opaque" choices made by the certifying bodies;

- the set of output parameters of the model guarantees the maximum information content as, thanks to the identified constraints, all three dimensions of sustainability are analyzed and the achievement of the minimum sustainability threshold is ensured;

- the parameters implemented by the model belong to the most widespread urban sustainability assessment procedures; this suggests that their use is shared more widely, at least, by users of such practices.

In other words, the set up grossing-up procedure of the parameters may constitute a simple and unburdensome evaluation tool to which the different end users of such practices may turn to, according to their needs. For example, public decision makers can use them to preliminarily assess the sustainability of urban transformation proposals, while citizens' associations, despite not having sufficient resources to monitor the executive process, can check/ascertain the negative effects of the 
plans and/or projects to be implemented. In this way, the aim of guaranteeing the sustainability at the neighborhood level can be more easily achieved, as well as the overall sustainability at the level of the whole city, in line with References [61,62], who state that the project and the design of the own component parts of a city influence the way of living of the whole urban community.

In addition, local decision-makers and public administrations can perceive this work as a lever to promote a constructive dialogue with consulting companies and non-governmental bodies who are developing this kind of procedures about their expensive fees.

Given the complexity of the subject matter of study, long-term future research efforts will be required to develop the ideas offered in this work from the methodological and practical point of view as a starting point. The first one could concern the new definition and assignment of weights to each parameter, considering that this is one of the critical aspects of the evaluation techniques. The second could deal with the application of more sophisticated multi-criteria decision analysis (MCDA) techniques enabling users to more explicitly take into account the three sustainability dimensions of a project. Indeed, in the present work, the three dimensions are implicitly considered in the constraints of the proposed linear programming model, whereas the main aim is minimizing the number of parameters that local administrators have to deal with and manage in a project. Finally, a further analysis may concern the application of the minimum set of parameters to projects already evaluated with the five protocols studied, to highlight their differences and/or similarities.

Author Contributions: Conceptualization, C.G.; Methodology, C.G. and F.Z.; Software, C.S. and F.Z.; Validation, C.S.; Formal Analysis, A.S.; Writing-Original Draft Preparation, F.Z.; Writing-Review \& Editing, C.S. and F.Z.

Funding: The research activity of the second and third author was partially funded by the University "Federico II" of Naples within the research project MOSTOLOG project (A multi-objective approach for Sustainable Logistic System).

Conflicts of Interest: The authors declare no conflict of interest.

\section{References}

1. Drexhage, J.; Murphy, D. Sustainable Development: From Brundtland to Rio 2012. Background Paper Prepared for Consideration by the High Level Panel on Global Sustainability at Its First Meeting, 19 September 2010. Available online: https://www.scribd.com/document/149351285/SustainableDevelopment-From-Brundtland-to-Rio-2012 (accessed on 19 September 2018).

2. Gupta, J.; Vegelin, C. Sustainable development goals and inclusive development. Int. Environ. Agreem. Politics Law Econ. 2016, 16, 433-448. [CrossRef]

3. Desa, U. World Urbanization Prospects: The 2011 Revision; Population Division, Department of Economic and Social Affairs, United Nations Secretariat: New York, NY, USA, 2014.

4. Pingali, P.L. Green revolution: Impacts, limits, and the path ahead. Proc. Natl. Acad. Sci. USA 2012, 109, 12302-12308. [CrossRef] [PubMed]

5. Basiago, A.D. Economic, social, and environmental sustainability in development theory and urban planning practice. Environmentalist 1998, 19, 145-161. [CrossRef]

6. De Jong, M.; Joss, S.; Schraven, D.; Zhan, C.; Weijnen, M. Sustainable-smart-resilient-low carbon-eco-knowledge cities; making sense of a multitude of concepts promoting sustainable urbanization. J. Clean. Prod. 2015, 109, 25-38. [CrossRef]

7. Sharifi, A.; Murayama, A. A critical review of seven selected neighborhood sustainability assessment tools. Environ. Impact Assess. Rev. 2013, 38, 73-87. [CrossRef]

8. Rajaonson, J.; Tanguay, G.A. A sensitivity analysis to methodological variation in indicator-based urban sustainability assessment: A Quebec case study. Ecol. Indic. 2017, 83, 122-131. [CrossRef]

9. McCool, S.F.; Stankey, G.H. Indicators of sustainability: Challenges and opportunities at the interface of science and policy. Environ. Manag. 2004, 33, 294-305. [CrossRef] [PubMed]

10. Elgert, L. Rating the sustainable city: 'Measurementality', transparency, and unexpected outcomes at the knowledge-policy interface. Environ. Sci. Policy 2018, 79, 16-24. [CrossRef]

11. Dizdaroglu, D. The Role of Indicator-Based Sustainability Assessment in Policy and the Decision-Making Process: A Review and Outlook. Sustainability 2017, 9, 1018. [CrossRef] 
12. Cappai, F.; Forgues, D.; Glaus, M. The Integration of Socio-Economic Indicators in the CASBEE-UD Evaluation System: A Case Study. Urban Sci. 2018, 2, 28. [CrossRef]

13. Richardson, T.; Cashmore, M. Power, knowledge and environmental assessment: The world bank's pursuit of 'good governance'. J. Political Power 2011, 4, 105-125. [CrossRef]

14. Berardi, U. Sustainability assessment of urban communities through rating systems. Environ. Dev. Sustain. 2013, 15, 1573-1591. [CrossRef]

15. Castanheira, G.; Bragança, L. The evolution of the sustainability assessment tool: From buildings to the built environment. Sci. World J. 2014, 2014, 491791. [CrossRef] [PubMed]

16. Komeily, A.; Srinivasan, R.S. A need for balanced approach to neighborhood sustainability assessments: A critical review and analysis. Sustain. Cities Soc. 2015, 18, 32-43. [CrossRef]

17. Marique, A.-F.; Reiter, S. Towards more sustainable neighbourhoods: Are good practices reproducible and extensible. In Proceedings of the International Conference PLEA, Louvain-la-Neuve, Belgium, 13-15 July 2011.

18. Sharifi, A. Sustainability at the Neighborhood Level: Assessment Tools and the Pursuit of Sustainability. Ph.D. Thesis, Nagoya University, Nagoya, Japan, 2013.

19. Lützkendorf, T.; Balouktsi, M. Assessing a sustainable urban development: Typology of indicators and sources of information. Procedia Environ. Sci. 2017, 38, 546-553. [CrossRef]

20. Karol, E.; Brunner, J. Tools for Measuring Progress towards Sustainable Neighborhood Environments. Sustainability 2009, 1, 612-627. [CrossRef]

21. Coplák, J.; Raksanyi, P. Planning Sustainable Settlements; Slavak University of Technology: Bratislava, Slovakia, 2003.

22. Haapio, A. Towards sustainable urban communities. Environ. Impact Assess. Rev. 2012, 32, 165-169. [CrossRef]

23. Orova, M.; Reith, A. Comparison and evaluation of neighbourhood sustainability assessment systems. In Proceedings of the PLEA2013 - 29th Conference, Sustainable Architecture for a Renewable Future, Munich, Germany, 10-12 September 2013.

24. Ameen, R.F.M.; Li, H.; Mourshed, M. Sustainability assessment methods of urban design: A review. In Proceedings of the 21st International Workshop: Intelligent Computing in Engineering, Cardiff, UK, 16-18 July 2014.

25. Haapio, A.; Viitaniemi, P. A critical review of building environmental assessment tools. Environ. Impact Assess. Rev. 2008, 28, 469-482. [CrossRef]

26. Gil, J.; Duarte, J.P. Tools for evaluating the sustainability of urban design: A review. Proc. Inst. Civ. Eng. Urban Des. Plan. 2013, 166, 311-325. [CrossRef]

27. Retzlaff, R.C. Green buildings and building assessment systems: A new area of interest for planners. J. Plan. Lit. 2009, 24, 3-21. [CrossRef]

28. Garde, A. Sustainable by design? Insights from US LEED-ND pilot projects. J. Am. Plan. Assoc. 2009, 75, 424-440. [CrossRef]

29. Kyrkou, D.; Karthaus, R. Urban sustainability standards: Predetermined checklists or adaptable frameworks? Procedia Eng. 2011, 21, 204-211. [CrossRef]

30. Shen, L.-Y.; Ochoa, J.J.; Shah, M.N.; Zhang, X. The application of urban sustainability indicators-A comparison between various practices. Habitat Int. 2011, 35, 17-29. [CrossRef]

31. Sharifi, A.; Murayama, A. Neighborhood sustainability assessment in action: Cross-evaluation of three assessment systems and their cases from the US, the UK, and Japan. Build. Environ. 2014, 72, 243-258. [CrossRef]

32. Reith, A.; Orova, M. Do green neighbourhood ratings cover sustainability? Ecol. Indic. 2015, 48, 660-672. [CrossRef]

33. Dawodu, A.; Akinwolemiwa, B.; Cheshmehzangi, A. A conceptual re-visualization of the adoption and utilization of the pillars of sustainability in the development of neighbourhood sustainability assessment tools. Sustain. Cities Soc. 2017, 28, 398-410. [CrossRef]

34. Jaeger, J.A.; Bertiller, R.; Schwick, C.; Kienast, F. Suitability criteria for measures of urban sprawl. Ecol. Indic. 2010, 10, 397-406. [CrossRef] 
35. Moussiopoulos, N.; Achillas, C.; Vlachokostas, C.; Spyridi, D.; Nikolaou, K. Environmental, social and economic information management for the evaluation of sustainability in urban areas: A system of indicators for Thessaloniki, Greece. Cities 2010, 27, 377-384. [CrossRef]

36. Crosbie, T.; Crilly, N.; Dawood, N.; Oliveras, J.; Niwaz, N. Visualising the 'Big Picture': Key Performance Indicators and Sustainable Urban Design. In Proceedings of the 1st Workshop Organised by the EEB Data Models Community ICT for Sustainable Places, Nice, France, 9-11 September 2013; pp. 11-26.

37. Braulio-Gonzalo, M.; Bovea, M.D.; Ruá, M.J. Sustainability on the urban scale: Proposal of a structure of indicators for the Spanish context. Environ. Impact Assess. Rev. 2015, 53, 16-30. [CrossRef]

38. Repetti, A.; Desthieux, G. A relational indicatorset model for urban land-use planning and management: Methodological approach and application in two case studies. Landsc. Urban Plan. 2006, 77, 196-215. [CrossRef]

39. Munier, N. Methodology to select a set of urban sustainability indicators to measure the state of the city, and performance assessment. Ecol. Indic. 2011, 11, 1020-1026. [CrossRef]

40. Reed, M.S.; Fraser, E.D.; Dougill, A.J. An adaptive learning process for developing and applying sustainability indicators with local communities. Ecol. Econ. 2006, 59, 406-418. [CrossRef]

41. Scipioni, A.; Mazzi, A.; Mason, M.; Manzardo, A. The Dashboard of Sustainability to measure the local urban sustainable development: The case study of Padua Municipality. Ecol. Indic. 2009, 9, 364-380. [CrossRef]

42. Tanguay, G.A.; Rajaonson, J.; Lefebvre, J.-F.; Lanoie, P. Measuring the sustainability of cities: An analysis of the use of local indicators. Ecol. Indic. 2010, 10, 407-418. [CrossRef]

43. Morgenstern, O.; Von Neumann, J. Theory of Games and Economic Behavior; Princeton University Press: Princeton, NJ, USA, 1953.

44. Zucaro, F. A critical review of parameters within urban sustainability models: How much do soil and natural resources weight? In Proceedings of the 9th International Conference on Innovation in Urban and Regional Planning, Titled Smart City: Planning for Energy, Transportation and Sustainability of the Urban System, Turin, Italy, 14-15 September 2016; pp. 214-219.

45. Sieber, S.; Amjath-Babu, T.; Reidsma, P.; Koenig, H.; Piorr, A.; Bezlepkina, I.; Mueller, K. Sustainability impact assessment tools for land use policy advice: A comparative analysis of five research approaches. Land Use Policy 2018, 71, 75-85. [CrossRef]

46. Boyle, L.; Michell, K.; Viruly, F. A critique of the application of neighborhood sustainability assessment tools in urban regeneration. Sustainability 2018, 10, 1005. [CrossRef]

47. BREEAM. Homepage of BREEAM. 2011. Available online: http://www.breeam.org/page.jsp?id=117 (accessed on 20 May 2018).

48. Papa, R. Il Governo delle Trasformazioni Urbane e Territoriali; Franco Angeli: Milano, Italy, 2009.

49. Rees, W.; Wackernagel, M. Urban ecological footprints: Why cities cannot be sustainable-And why they are a key to sustainability. Environ. Impact Assess. Rev. 1996, 16, 223-248. [CrossRef]

50. Webb, R.; Bai, X.; Smith, M.S.; Costanza, R.; Griggs, D.; Moglia, M.; Neuman, M.; Newman, P.; Newton, P.; Norman, B. Sustainable urban systems: Co-design and framing for transformation. Ambio 2018, 47, 57-77. [CrossRef] [PubMed]

51. Icaza, L.E.; Van der Hoeven, F.; Van den Dobbelsteen, A. Surface thermal analysis of North Brabant cities and neighbourhoods during heat waves. TEMA J. Land Use Mobil. Environ. 2016, 9, 63-87.

52. Gargiulo, C.; Tulisi, A.; Zucaro, F. Climate change-oriented urban green network design: A decision support tool. In Network Design and Optimization for Smart Cities; World Scientific: Singapore, 2017; pp. 255-278.

53. Zucaro, F.; Morosini, R. Sustainable land use and climate adaptation: A review of European local plans. TEMA J. Land Use Mobil. Environ. 2018, 11, 7-26.

54. Du, P.; Wood, A.; Ditchman, N.; Stephens, B. Life Satisfaction of Downtown High-Rise vs. Suburban Low-Rise Living: A Chicago Case Study. Sustainability 2017, 9, 1052. [CrossRef]

55. Wright, P.A.; Kloos, B. Housing environment and mental health outcomes: A levels of analysis perspective. J. Environ. Psychol. 2007, 27, 79-89. [CrossRef] [PubMed]

56. Bond, A.J.; Morrison-Saunders, A. Re-evaluating sustainability assessment: Aligning the vision and the practice. Environ. Impact Assess. Rev. 2011, 31, 1-7. [CrossRef]

57. Gasparatos, A.; Scolobig, A. Choosing the most appropriate sustainability assessment tool. Ecol. Econ. 2012, 80, 1-7. [CrossRef] 
58. Holden, M.; Li, C.; Molina, A. The emergence and spread of ecourban neighbourhoods around the world. Sustainability 2015, 7, 11418-11437. [CrossRef]

59. Leone, A.; Gobattoni, F.; Pelorosso, R. Sustainability and planning. Thinking and acting according to thermodinamics laws. TEMA J. Land Use Mobil. Environ. 2014. [CrossRef]

60. Papa, R. Editorial Preface. Cities, Energy and Built Environment. TEMA J. Land Use Mobil. Environ. 2015, 8, 129-130.

61. Choguill, C.L. Developing sustainable neighborhoods. Habitat Int. 2008, 32, 41-48. [CrossRef]

62. Zhang, Q.; Yung, E.H.K.; Chan, E.H.W. Towards Sustainable Neighborhoods: Challenges and Opportunities for Neighborhood Planning in Transitional Urban China. Sustainability 2018, 10, 406. [CrossRef]

C 2018 by the authors. Licensee MDPI, Basel, Switzerland. This article is an open access article distributed under the terms and conditions of the Creative Commons Attribution (CC BY) license (http://creativecommons.org/licenses/by/4.0/). 